\title{
Geckos decouple fore- and hind limb kinematics in response to changes in incline
}

\author{
Aleksandra V. Birn-Jeffery ${ }^{1,2^{*}}$ and Timothy E. Higham²
}

\begin{abstract}
Background: Terrestrial animals regularly move up and down surfaces in their natural habitat, and the impacts of moving uphill on locomotion are commonly examined. However, if an animal goes up, it must go down. Many morphological features enhance locomotion on inclined surfaces, including adhesive systems among geckos. Despite this, it is not known whether the employment of the adhesive system results in altered locomotor kinematics due to the stereotyped motions that are necessary to engage and disengage the system. Using a generalist pad-bearing gecko, Chondrodactylus bibronii, we determined whether changes in slope impact body and limb kinematics.

Results: Despite the change in demand, geckos did not change speed on any incline. This constant speed was achieved by adjusting stride frequency, step length and swing time. Hind limb, but not forelimb, kinematics were altered on steep downhill conditions, thus resulting in significant de-coupling of the limbs.

Conclusions: Unlike other animals on non-level conditions, the geckos in our study only minimally alter the movements of distal limb elements, which is likely due to the constraints associated with the need for rapid attachment and detachment of the adhesive system. This suggests that geckos may experience a trade-off between successful adhesion and the ability to respond dynamically to locomotor perturbations.
\end{abstract}

Keywords: Gecko, Incline, Decline, Adhesive system, Forelimb, Hind limb

\section{Background}

Animals move through complex environments, which require them to deal with a number of important factors, such as differing slopes, textures, and perturbations. However, most research focusing on locomotor biomechanics has examined level locomotion [1-6]. Because of this, it is unclear whether there is a common neuromechanical template for inclined locomotion across species, as has been observed for level locomotion [3, 7-9]. Although going up is critical for most terrestrial animals, coming back down may be just as critical, if not more important [10]. The locomotor strategies for descending are unknown, but may be enhanced by morphological features such as claws or adhesive structures [11].

\footnotetext{
* Correspondence: ab2265@cam.ac.uk

'Department of Zoology, University of Cambridge, Downing Street, Cambridge, UK

${ }^{2}$ Department of Biology, University of California, 900 University Avenue, Riverside, CA 92521, USA
}

Moving uphill requires an animal to move against gravity, requiring more work compared to level surfaces [12]. On inclines, a backwards toppling moment depends on the steepness of the slope, is caused by the rotation of the body with respect to gravity, along with the placement of the base of support, and must be overcome or reduced. The majority of species tend to adopt a more crouched posture to reduce this toppling moment on inclines, which is often achieved by greater flexion at the elbow and/or knee [13-16]. To account for the increased work requirement, and to reduce musculoskeletal stresses, the majority of animals also reduce their speed [14, 17-22], and increase duty factor $[13,23,24]$ on inclines to increase contact time, mainly in order to decrease peak forces, but this may have consequences for improving the stability of the animal on inclines as well.

Unlike moving uphill, downhill locomotion is poorly studied [10]. There is also a toppling moment associated with downhill locomotion, but, unlike uphill locomotion, 
it causes a forward toppling moment that results in an increased reliance on braking. Most animals reduce their speed on declines, compared to level terrain locomotion $[18,20,25,26]$, but variables such as stride frequency exhibit large differences between studies [23, 24, 27]. There is a continuing lack of agreement in many parameters such as speed, muscle activity and the metabolic cost of locomotion on downhill surfaces [23, 27-30], along with the numerous different animal models that have been used, so currently it is difficult to determine if a common locomotor strategy exists for downhill surfaces (see Birn-Jeffery \& Higham [10] for review). The specialised adhesive system on the feet of geckos likely further drives greater variation in strategies for moving downhill.

Geckos are a highly successful group, found in many ecological niches [31]. The adhesive system of geckos is an innovation that permits the occupation of ecological niches that were not previously available, thus allowing them to extensively radiate [32]. Gecko adhesion is very strong [33, 34] and achieved through close contact between the surface and setae on the ventral surface of the toes [35-37]. This close contact results in van der Waal interactions [38], frictional forces [39] and contact electrification [40], which collectively result in adhesion. To prevent adhesive forces on surfaces that do not require adhesion, such as level terrain, geckos keep their digits in a hyperextended position [21]. This prevents the setae from contacting the surface and thus prevents interactions such as van der Waals. Previous work has focussed on these adhesive mechanisms, including the physical interactions causing adhesion [33, 38-41] and the stereotyped micromechanics of the setae [42-47]. Yet, we currently do not understand how the adhesive system constrains overall body and limb mechanics, which is likely, given the requirement of stereotyped motions to engage and disengage this innovation.

The impact of the adhesive system on locomotor kinematics among geckos is poorly understood (but see [48]); but spatiotemporal characteristics have previously been studied. The gaits that geckos use on level terrain are similar to other legged animals (i.e. vaulting and bouncing gaits [49]). Rather than changing speed through a combination of stride length and stride frequency, geckos commonly rely solely on alterations in stride frequency on both level and inclined terrains $[22,50-52]$. The adhesive system may play a key role in successful incline locomotion, but it could also severely constrain locomotion. This is evident in the lack of change in timing of deploying and detaching the adhesive system between different terrains $[21,52,53]$, and reductions in maximal speed associated with larger toe pad areas [54]. Therefore we still do not understand the impact that the adhesive system has on locomotion.
Using a generalist pad-bearing gecko, Chondrodactylus bibronii, we investigated whole body and limb kinematics on differing slopes (both uphill and downhill). Although C. bibronii is considered a generalist [55], they are highly capable climbers with a good adhesive system [56]. Due to the specialisation of the manus and pes for accommodating the adhesive system, we expect that distal limb movements will be less modulated and more stereotyped to provide successful adhesion and detachment. We therefore hypothesise that geckos will modulate humeral/femoral and elbow/knee motions to a greater extent than more distal limb segments, with this effect becoming emphasised on steeper slopes in order to overcome gravity. We expect that proximal forelimb joints will undergo smaller angular excursions on steep declines to prevent toppling downhill, whilst on steep inclines greater angular excursions will provide increased contact time over which to produce extra work to climb uphill. As with previous incline studies we expect that speed will be reduced on inclines, but that this will be adjusted mainly by changes in stride frequency.

\section{Results}

\section{Spatio-temporal characteristics}

Neither $10^{\circ}$ incline nor decline conditions had any significant differences in spatio-temporal variables (e.g. stance time, step length) in either forelimbs or hind limbs from level (Table 1). Forward speed and duty factor also did not significantly differ between any conditions (Table 1). Thus due to the low range of speeds observed the effects of speed on both limb movements and spatio-temporal variables are negligible. Swing time was significantly reduced by $50 \%$ and $17 \%$ in the forelimb and hind limb respectively, for the $-45^{\circ}$ condition compared to all other slopes (Table 1). The reduction in swing time only resulted in a significant decrease in stride time in the forelimb (Table 1). Stride frequency significantly increased by $54 \%$ in the forelimb as compared to level, but was not significantly different to the level stride frequency in the hind limb (Table 1). Step and stride length were significantly reduced by $26 \%$ on the $-45^{\circ}$ slope in the hind limb as compared to all other conditions (Table 1).

\section{Posture changes on sloped terrain}

Shoulder and hip height at footfall (FF), mid-stance (MS) and end stance (ES) on inclines did not significantly differ from level (Table 2). The virtual leg length at FF increased in the hind limb on the downhill $45^{\circ}$ condition (level: $0.021 \mathrm{~m} ;-45^{\circ}$ : $0.024 \mathrm{~m}$ ), but significantly decreased at ES (level: $0.042 \mathrm{~m} ;-45^{\circ}: 0.039 \mathrm{~m}$; Table 2). The elevation angle (angle of the virtual leg from the ground along the vertical-medio-lateral plane) was significantly reduced in the forelimb at ES on $-45^{\circ}$ incline 
Table 1 Means and ANOVA results for spatio-temporal variables for the forelimb and hind limb

\begin{tabular}{|c|c|c|c|c|c|c|c|}
\hline & \multirow{2}{*}{$\begin{array}{l}\text { Mean } \pm \text { s.e.m. } \\
\text { Level }\end{array}$} & \multicolumn{4}{|c|}{ Difference from level } & \multirow{2}{*}{$\begin{array}{l}\text { F-statistic } \\
\text { (degrees of freedom) }\end{array}$} & \multirow[t]{2}{*}{$P$-value } \\
\hline & & $+10^{\circ}$ & $+45^{\circ}$ & $-45^{\circ}$ & $-10^{\circ}$ & & \\
\hline Velocity $\left(\mathrm{ms}^{-1}\right)$ & $0.57 \pm 0.067$ & $0.03 \pm 0.061$ & $-0.02 \pm 0.052$ & $0.12 \pm 0.057$ & $-0.05 \pm 0.031$ & - & - \\
\hline Velocity $\left(\mathrm{ms}^{-1} / \mathrm{sqrt}\left(\mathrm{ms}^{-2 \mathrm{a}} \mathrm{SVL}\right)\right)$ & $0.67 \pm 0.055$ & $0.02 \pm 0.059$ & $-0.01 \pm 0.053$ & $0.13 \pm 0.065$ & $-0.06 \pm 0.029$ & $1.50(4,20)$ & 0.24 \\
\hline \multicolumn{8}{|l|}{ Forelimb } \\
\hline$T_{\text {stance }}(\mathrm{s})$ & $0.08 \pm 0.008$ & $-0.01 \pm 0.008$ & $0.00 \pm 0.010$ & $-0.02 \pm 0.008$ & $0.01 \pm 0.007$ & $1.54(4,20)$ & 0.23 \\
\hline $\mathrm{T}_{\text {swing }}(\mathrm{s})$ & $0.06 \pm 0.003$ & $0.00 \pm 0.002$ & $0.00 \pm 0.004$ & $-0.03 \pm 0.003^{\mathrm{a}}$ & $0.00 \pm 0.004$ & $9.61(4,20)$ & $<0.005$ \\
\hline $\mathrm{T}_{\text {stride }}(\mathrm{s})$ & $0.14 \pm 0.010$ & $-0.01 \pm 0.010$ & $0.00 \pm 0.011$ & $-0.05 \pm 0.010^{a}$ & $0.01 \pm 0.009$ & $3.61(4,20)$ & 0.02 \\
\hline DF & $0.56 \pm 0.024$ & $-0.02 \pm 0.020$ & $0.00 \pm 0.030$ & $0.07 \pm 0.025$ & $0.01 \pm 0.016$ & $1.13(4,20)$ & 0.37 \\
\hline Stride Freq $(\mathrm{Hz})$ & $7.76 \pm 0.592$ & $0.07 \pm 0.56$ & $0.03 \pm 0.588$ & $4.16 \pm 0.977^{\mathrm{a}}$ & $-0.42 \pm 0.415$ & $5.45(4,20)$ & $<0.005$ \\
\hline Step Length (m/SVL) & $0.58 \pm 0.009$ & $-0.01 \pm 0.007$ & $-0.05 \pm 0.009$ & $-0.10 \pm 0.002$ & $-0.00 \pm 0.007$ & $1.13(4,20)$ & 0.31 \\
\hline Stride Length $(\mathrm{m} / \mathrm{SVL})$ & $0.91 \pm 0.015$ & $0.00 \pm 0.022$ & $-0.08 \pm 0.009$ & $-0.17 \pm 0.014$ & $0.14 \pm 0.047$ & $0.76(4,20)$ & 0.40 \\
\hline \multicolumn{8}{|l|}{ Hind limb } \\
\hline$T_{\text {stance }}(\mathrm{s})$ & $0.09 \pm 0.008$ & $-0.00 \pm 0.014$ & $0.02 \pm 0.013$ & $-0.01 \pm 0.015$ & $0.02 \pm 0.007$ & $1.30(4,20)$ & 0.30 \\
\hline $\mathrm{T}_{\text {swing }}(\mathrm{s})$ & $0.05 \pm 0.003$ & $0.00 \pm 0.002$ & $-0.00 \pm 0.003$ & $-0.01 \pm 0.003^{a}$ & $0.00 \pm 0.003$ & $4.56(4,20)$ & 0.008 \\
\hline $\mathrm{T}_{\text {stride }}(\mathrm{s})$ & $0.14 \pm 0.009$ & $-0.00 \pm 0.015$ & $0.02 \pm 0.015$ & $-0.03 \pm 0.018$ & $0.02 \pm 0.006$ & $1.85(4,20)$ & 0.16 \\
\hline DF & $0.62 \pm 0.022$ & $-0.01 \pm 0.038$ & $0.04 \pm 0.021$ & $0.02 \pm 0.033$ & $0.04 \pm 0.025$ & $0.48(4,20)$ & 0.75 \\
\hline Stride Freq $(\mathrm{Hz})$ & $7.51 \pm 0.521$ & $-0.17 \pm 0.797$ & $-0.44 \pm 0.708$ & $2.36 \pm 1.264$ & $-1.18 \pm 0.358$ & $2.75(4,20)$ & 0.06 \\
\hline Step Length (m/SVL) & $0.61 \pm 0.018$ & $-0.03 \pm 0.024$ & $-0.05 \pm 0.009$ & $-0.16 \pm 0.023^{a}$ & $-0.05 \pm 0.009$ & $8.21(4,20)$ & $<0.005$ \\
\hline Stride Length $(\mathrm{m} / \mathrm{SVL})$ & $0.99 \pm 0.046$ & $-0.06 \pm 0.053$ & $-0.10 \pm 0.035$ & $-0.25 \pm 0.020^{a}$ & $-0.12 \pm 0.041$ & $4.36(4,20)$ & 0.02 \\
\hline
\end{tabular}

$T$ is time, $D F$ is duty factor and SVL is snout-vent length

${ }^{a}$ Denotes significant differences from level

as compared to level (Table 2). Hind limb elevation angle was significantly reduced at $\mathrm{FF}$, from level, in the $-45^{\circ}$ condition (Table 2). The placement of the forelimb foot (azimuth angle) did not significantly change from level in any of the conditions (Table 2), but the hind limb at $\mathrm{FF}$, in the $-45^{\circ}$ condition was placed in a significantly more posterior position compared to all other conditions (level: $171.49^{\circ} ;-45^{\circ}$ : 201.82; Table 2).

\section{Limb kinematics}

The forelimb joint angles, compared to the hind limb, had fewer significant changes on inclines compared to level (Fig. 1). The only significant changes in the forelimb, compared to level, were at ES; the elbow was significantly more flexed, by $25 \%$, on the $-45^{\circ}$ incline $\left(F_{4,20}=4.19 ; p=\right.$ 0.013 ) and the metacarpalphalangeal (MCP) joint was significantly more extended, by $33 \%$, on the $45^{\circ}$ incline $\left(F_{4,20}=3.91 ; p<0.017\right)$. No significant differences from level occurred in humeral or pectoral girdle rotation in any of the other conditions.

The hind limb joint trajectories deviated more from those on the level terrain in both the $+45^{\circ}$ and $-45^{\circ}$ conditions compared to the forelimbs (Fig. 1). Clockwise femur rotation was significantly greater at FF and MS on the $-45^{\circ}$ condition (Fig. 2 ; at MS: $F_{4,20}=4.72 ; p=0.007$ ), and the femur was more depressed compared to level during MS and ES in that terrain. Incline did not significantly impact femur retraction. The knee was $22 \%$ more flexed at FF for the $-45^{\circ}$ incline $\left(F_{4,20}=7.75\right.$; $p<0.005)$, but did not significantly differ from level at either MS or ES. The ankle only significantly differed from level at MS for the $-10^{\circ}$ and $-45^{\circ}$ inclines $\left(F_{4,20}=\right.$ $7.34 ; p<0.005)$; in both cases the ankle was more extended by $37 \%$ and $50 \%$ respectively. As with pectoral girdle, the pelvic girdle had a consistently similar rotation trajectory in each condition (Fig. 2).

The angular excursion swept by each forelimb joint during the stance phase did not differ between any inclines. Conversely, there were significant reductions in the angular excursion of hind limb joints for the $-45^{\circ}$ incline compared to all other conditions (Fig. 3). The ankle $\left(F_{4,20}=4.26 ; p=0.012\right)$ swept through a significantly smaller range on the $-45^{\circ}$ condition as compared to all other inclines. The knee and metatarsalphalangeal (MTP) joints also swept through a smaller range of angles on the $-45^{\circ}$ condition by $19 \%$ and $25 \%$ respectively compared to all other conditions.

\section{Changes in modulation between limbs}

In the majority of cases the hind limbs exhibited significantly greater modulation on inclined conditions compared to level terrain in contrast to the forelimbs (Table 3). In all cases where variables differed from level terrain at FF, such as humerus/femur rotation, depression 
Table 2 Means and ANOVA results for postural variables for the forelimbs and hind limb

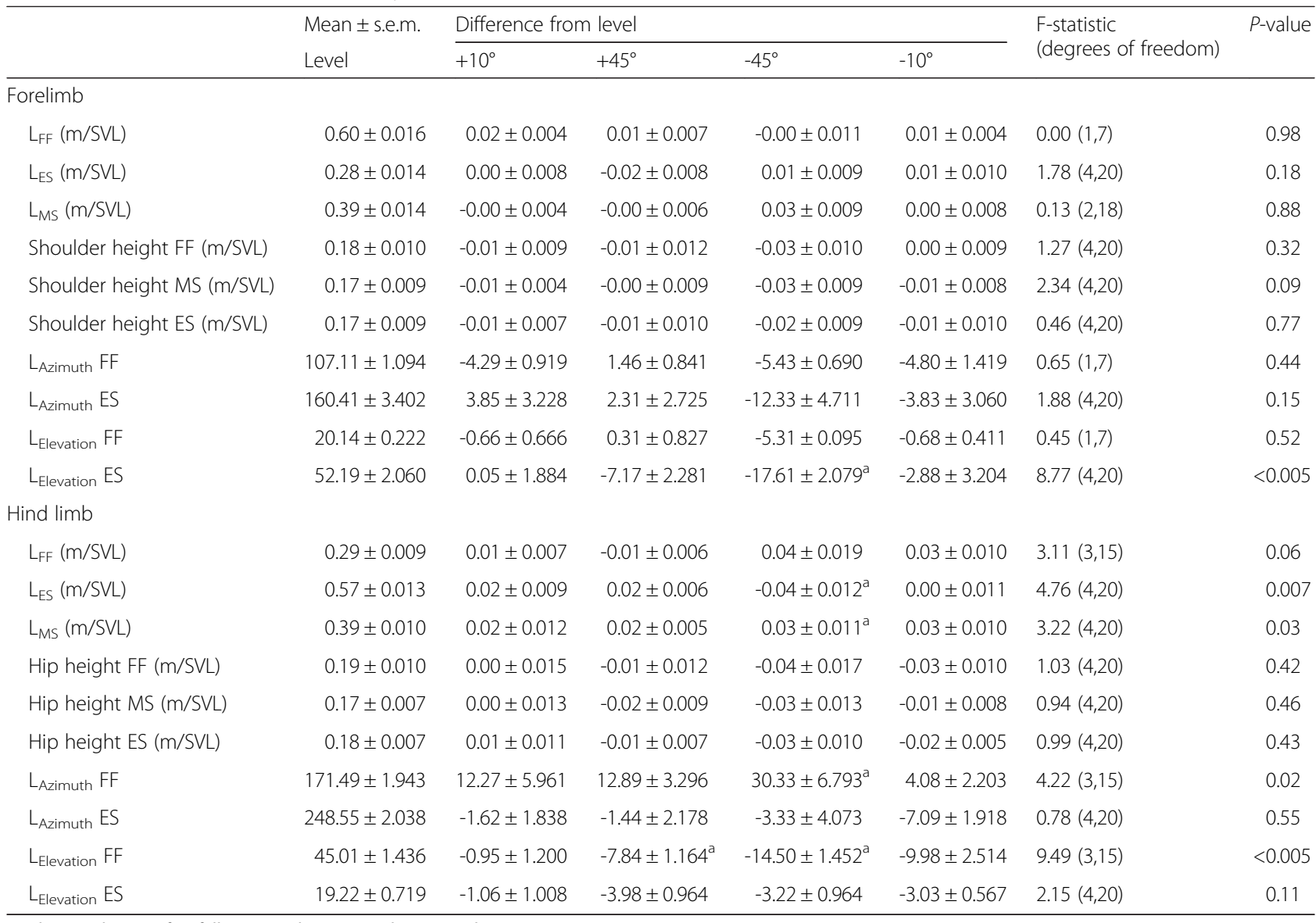

$L$ is leg, $F F$ denotes footfall, $E S$ is end stance and $M S$ is mid stance

${ }^{a}$ Denotes significant differences from level

and elbow/knee angle, the hind limb exhibited the greatest change in kinematics (Table 3). These differences were greatest on either the $+45^{\circ}$ or $-45^{\circ}$ inclines. Interestingly, the forelimb was modulated significantly more than the hind limb in humeral versus femoral rotation and depression at ES (Table 3).

\section{Discussion}

Chondrodactylus bibronii does not substantially change limb kinematics when moving on shallow slopes compared to level (Fig. 1). In addition, the geckos employed strategies to maintain speed on steep slopes (Table 1) via significant modulation of the hind limb whilst using similar forelimb movement patterns to those observed during level locomotion. Minimal changes in forelimb joint trajectories allow geckos to retain this limb to power or brake, depending on terrain. The hind limbs, on the other hand, are drastically adjusted on downhill slopes, resulting in them facing backwards, and it is therefore unlikely that they play any role in powering locomotion in these conditions [11]. Instead, the hind limb could be used to compensate for the braking requirements, any medio-lateral imbalance as well as dealing with the forward toppling moment during downhill locomotion. Where significant changes in limb kinematics occur for C. bibronii, they are generally limited to the more proximal joints. Therefore, although adhesion facilitates successful locomotion on many surfaces, it may also constrain locomotor mechanics. This may then result in large changes at the more proximal joints in non-level terrain, rather than adjusting kinematics at distal locations which may indicate a more feedforward driven locomotor control.

\section{Spatio-temporal characteristics}

Geckos do not change the timing of limb movements on uphill surfaces compared to level (Table 1). This is drastically different to previous studies of inclined locomotion where significant increases in stride time $[24,57]$ and duty factor $[13,23,24]$ are evident. Duty factor often increases on uphill surfaces, allowing greater time in contact with the ground to provide the extra work required to move against gravity. Collectively, this results in decreased speed on uphill surfaces [18, 19, 21, 58-61], but we do not observe this in the geckos in our study. 

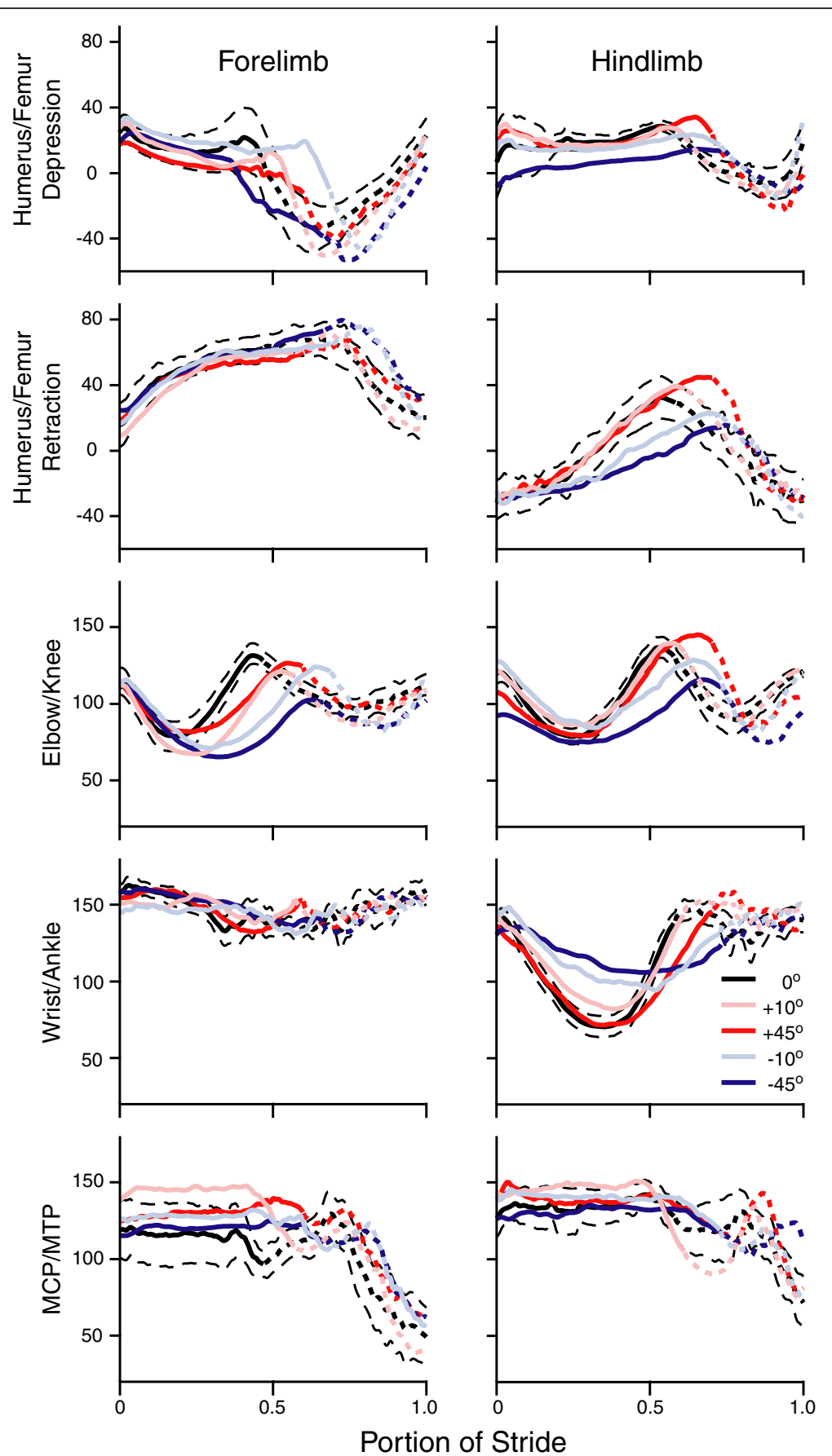

Fig. 1 Average limb angle trajectory plots across all conditions for both forelimbs and hind limbs. Solid lines represent the stance phase, whilst short dashed lines represent the swing phase. The long dashed, black lines are the $95 \%$ confidence intervals for the level terrain. The hind limb had the greatest limb angle trajectory changes from level condition compared to the forelimb, particularly at the ankle. The forelimb had greater timing changes associated with sloped locomotion

Russell and Higham [21] examined species of pad-bearing and padless geckos, and found that a trade-off exists between adhesion on inclines and running speed. In this case, the pad-bearing species slowed down on inclines of $10^{\circ}$ and greater compared to level locomotion, whereas the padless species did not [21]. In contrast, our results suggest that a trade-off may not exist for $C$. bibronii as they engage the adhesive system at steeper inclines without a decrease in running performance. The time to engage and disengage the gecko adhesive system does not change across conditions [52, 53], which suggests that $C$. bibronii is compensating for adhering to the surface by 


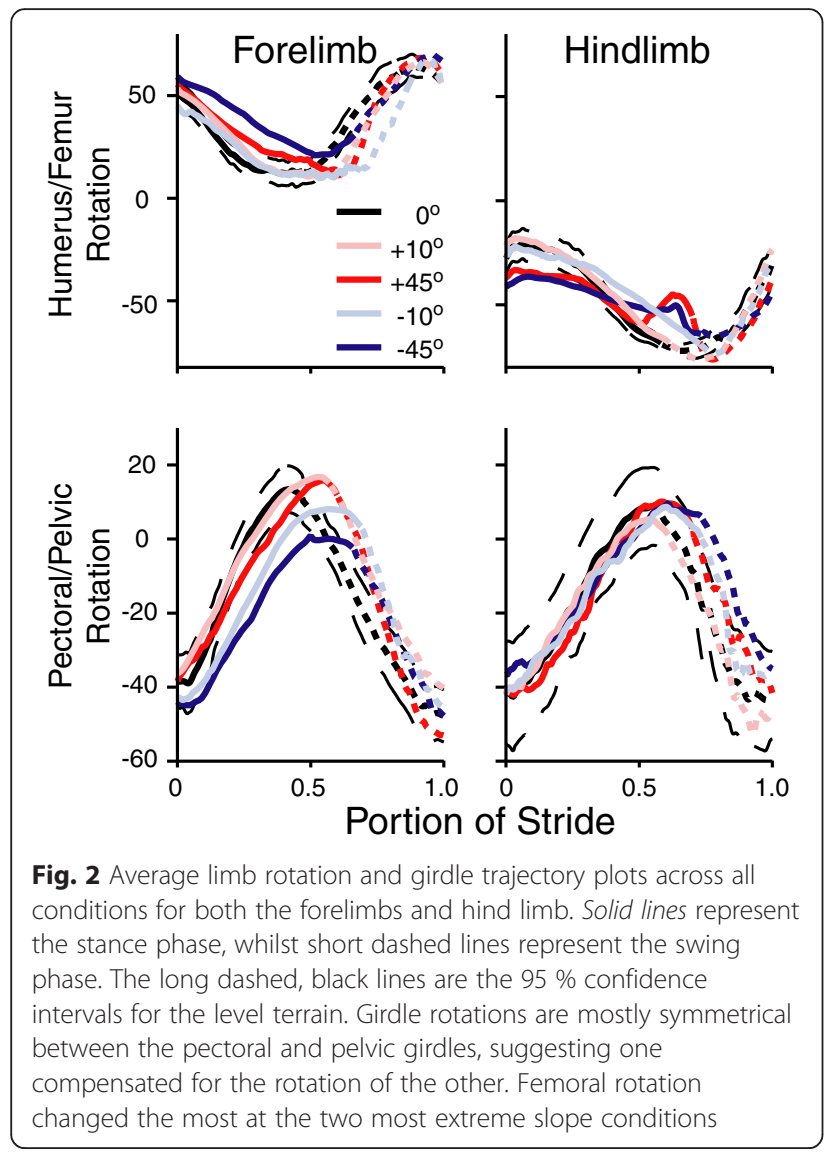

Fig. 2 Average limb rotation and girdle trajectory plots across all conditions for both the forelimbs and hind limb. Solid lines represent the stance phase, whilst short dashed lines represent the swing phase. The long dashed, black lines are the $95 \%$ confidence between the pectoral and pelvic girdles, suggesting one compensated for the rotation of the other. Femoral rotation adjusting other parameters, such as stride frequency or length. Understanding the trade-off between using an adhesive system and performance in geckos requires future work to determine how and whether differing adhesive systems in geckos differentially affect locomotor performances on sloped surfaces.

One possible tactic for maintaining speed and stance time is to reduce swing time. Many previous studies have noted no significant changes in swing time on inclines compared to level [15, 28, 53, 62-67]. Remarkably swing time did decrease on the $45^{\circ}$ decline condition from level in our study (Table 1). Reduction in swing time compared to level terrain has previously been noted in birds on inclines $[23,68]$. Shortening the swing time, whilst keeping stance time constant, could be a strategy to maintain relatively consistent peak forces, as well as provide enough time for producing an impulse that can generate work for going uphill, or absorb energy (negative work) when moving downhill. Decreasing stance time, particularly in terrain conditions that require more work, also requires greater peak forces. Greater peak forces are associated with increased bone and muscle stresses [69], suggesting that animals may use strategies that allow the greatest time in contact with the ground to reduce these stresses. One strategy to do this, but still maintain speed, would be to reduce swing time as we observed for geckos.

A reduction in swing time also suggests a neuromechanical control strategy involving something other than passive pendular movements of the limb, where limbs swing purely under the effect of gravity $[9,70]$. Instead, it is likely that the limb is swung faster, thus increasing

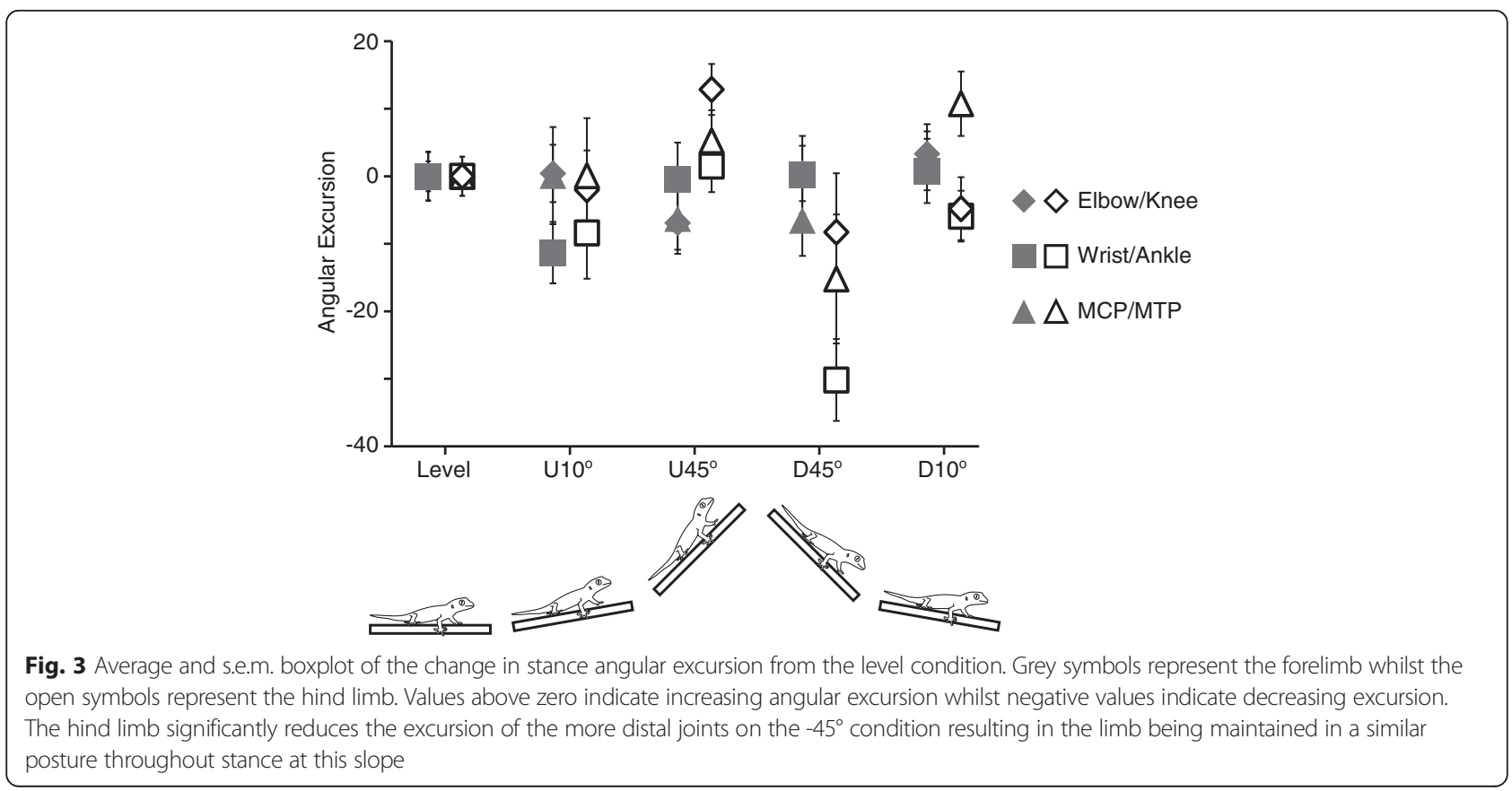


Table 3 Significant t-test results for the modulation difference between fore and hind limbs

\begin{tabular}{|c|c|c|c|c|c|}
\hline & $\begin{array}{l}\text { Terrain } \\
\text { condition }\end{array}$ & $\begin{array}{l}\text { Forelimb difference } \\
\text { from level }\end{array}$ & $\begin{array}{l}\text { Hindlimb difference } \\
\text { from level }\end{array}$ & T-statistic & $p$-value \\
\hline FF humerus vs femur rotation & $+45^{\circ}$ & 2.536 & -14.993 & 2.205 & $0.043^{\mathrm{a}}$ \\
\hline FF humerus vs femur rotation & $-45^{\circ}$ & 9.902 & -18.477 & 2.091 & $0.047^{\mathrm{a}}$ \\
\hline ES humerus vs femur rotation & $-45^{\circ}$ & 17.220 & 1.953 & 2.593 & 0.016 \\
\hline FF humerus vs femur depression & $+10^{\circ}$ & -0.571 & 15.229 & 3.413 & $0.006^{a}$ \\
\hline ES humerus vs femur depression & $+10^{\circ}$ & -29.867 & -0.251 & 2.698 & 0.018 \\
\hline ES humerus vs femur depression & $+45^{\circ}$ & -14.100 & 0.593 & 3.22 & 0.006 \\
\hline ES humerus vs femur depression & $-45^{\circ}$ & -50.658 & -11.626 & 3.93 & 0.001 \\
\hline FF elbow vs knee angle & $-45^{\circ}$ & -8.652 & -27.044 & 2.152 & $0.047^{a}$ \\
\hline FF pectoral vs pelvic girdle rotation & $-10^{\circ}$ & -1.437 & 4.450 & 2.431 & $0.045^{a}$ \\
\hline FF pectoral vs pelvic girdle rotation & $-45^{\circ}$ & -2.497 & 14.812 & 2.499 & $0.032^{\mathrm{a}}$ \\
\hline Angular excursion wrist vs ankle & $-45^{\circ}$ & 0.213 & -30.167 & 2.211 & $0.036^{a}$ \\
\hline Angular excursion MCP vs MTP & $-45^{\circ}$ & -6.531 & -15.211 & 2.608 & $0.015^{a}$ \\
\hline FF Limb elevation angle & $-45^{\circ}$ & -5.307 & -17.607 & 2.338 & $0.044^{a}$ \\
\hline
\end{tabular}

Values are reported in degree $\left(^{\circ}\right)$ differences

$F F$ is footfall and $E S$ denotes end stance

${ }^{\mathrm{a}}$ Represents where hind limbs were modulated to a greater extent than forelimbs

the energetic cost of the swing phase [71, 72]. Several studies have noted swing leg velocity manipulations in non-level terrain [73-75], which can improve stability $[76,77]$ and can reduce peak leg forces and falls $[78,79]$. The reduction in swing time in geckos will also bring the foot back into contact with the ground earlier, which is advantageous for an animal that has, and uses, an adhesive system. This reduction in swing time during downhill running may be a compensatory strategy to provide the animal with a greater portion of the stride in adhesion, but we still do not fully understand the consequences of shortening the swing time. As mentioned above, alteration to the leg swing can affect both the ability to successfully continue moving in complex terrain and leg forces, so future work should determine if a trade-off exists between increasing time for adhering and maintaining lower leg forces to reduce musculoskeletal stress.

\section{Posture changes on non-level terrain}

Surprisingly, geckos do not crouch more on slopes as compared to level (Table 2). In our study, C. bibronii, maintained the level forelimb posture on all slopes, with only a slightly more crouched posture at ES on the $-45^{\circ}$ slope. The hind limb was more crouched on the $+45^{\circ}$ and $-45^{\circ}$ slopes, compared to level. Previous studies on a range of vertebrate taxa note a significantly more crouched posture on both uphill $[13-16,80]$ and downhill slopes [14-16, 30, 81], in a variety of gradients of $5-45^{\circ}$ both on inclines and declines. Geckos are sprawled postured animals, and the species of gecko used here is small, so its centre of mass is closer to the substrate. Thus, if the sprawled posture is simply maintained then there might be a small and likely insignificant toppling moment associated with locomotion on slopes. This reduces the necessity for the gecko to change posture on slopes. Future work using force plates to allow measurements of centre of mass will corroborate this interpretation. Other small lizards do adopt a more crouched posture on inclines [13]; but these animals were run on dowels (curved surfaces), so a postural effect may be linked with perch shape rather than incline. Another aspect is the adhesive system; this species of gecko can adhere strongly to surfaces [56]. This may implicitly be an advantage, allowing them to adhere on both inclines and declines [11], thus removing the need for postural changes on slopes as the adhesive system is significantly overbuilt [33] and can provide enough adhesive force to counteract any toppling moments.

\section{Differential limb modulation}

Hind limb kinematics on inclines and declines, relative to level, are modulated to a greater extent than forelimb kinematics (Table 3), suggesting a functional de-coupling of the two sets of limbs. Particularly in the $-45^{\circ}$ condition stance angular excursion in the more distal hind limb joints is greatly reduced than in other conditions (Fig. 3). Therefore, when moving on steep declines, $C$. bibronii significantly modifies the position of the hind limb, with digits becoming more posteriorly rotated [11]. Along with the reduction in angular excursion of the distal limbs, this results in the hind limb maintaining a constant rear-facing position throughout the stance phase. The hind limb is maintained in a more posterior position to allow the adhesive system to engage [11]. In particular, this rotation is partially achieved through the 
ankle, which exhibits a significantly lower angular excursion in the $-45^{\circ}$ condition, further suggesting a functional change in the hind limb. Conversely, the wrist joint trajectory remains constant across all conditions (Fig. 1). The maintenance of the wrist joint in geckos is very different to other lizard and mammal locomotor studies where the wrist undergoes significant changes dependent upon terrain condition [13, 57, 81, 82]. This suggests that the constraint seen in wrist movement in C. bibronii is likely a result of the adhesive system, but this does require future investigation in other geckos to determine if there is a link between wrist movement constraints and possession of an adhesive system.

Although the majority of changes occur in the hind limb, the movements of the forelimbs are also adjusted on the $-45^{\circ}$ condition. Humeral depression is reduced, resulting in greater humeral elevation at ES. When combined with a more flexed elbow (Fig. 1), this brings the front of the body closer to the surface, increasing the braking capacity of the limb but decreasing propulsion at ES. On steep downhill slopes the braking capacity is more important than propulsion as it helps prevent a headlong rush downhill. Locomotion on slopes appears to induce a de-coupling of limb function in animals where fore- and hind limbs are modified differently dependent on condition $[19,53,83,84]$; on declines forelimbs are used for braking whereas on uphill slopes hind limbs power locomotion. Our current work indicates that geckos significantly modulate hind limb, but not forelimb, movements. The reduction of modulation in forelimbs, on both uphill and downhill conditions, may suggest that it is the dominant limb for providing work and power; this could be achieved on inclines by using the adhesive system to help pull the gecko upwards similar to chameleons $[81,85]$. The hind limb also appears to have a greater range of motion [86], thus allowing it to be modulated to a greater extent than forelimbs on non-level terrain. This allows the hind limb to adjust to the locomotor requirements such as providing the necessary stability, both medio-laterally and cranio-caudally to prevent toppling in each terrain condition. However, future studies should obtain single forelimb and hind limb footfalls of geckos on force plates to define how the limbs function individually and in different terrain conditions.

Chondrodactylus bibronii minimally alters distal limb kinematics on sloped terrains compared to other animals. On $45^{\circ}$ inclines the MCP is significantly more extended at ES whilst the MTP joint trajectory is steadily maintained on all conditions. This extension of the MCP may provide increased 'push-off' at ES with which to help propel the animal forward against gravity. Apart from this one difference, MCP and MTP joints are remarkably consistent on all other conditions, particularly during stance. The motion to engage and disengage the adhesive system is very stereotyped [36], and so geckos are more likely to alter proximal joints to provide extra work rather than altering distal joints that could affect the success of their adhesive capabilities [87]. Interestingly, this would be converse to the majority of other animals, where a proximal-distal gradient is observed. In these cases smaller feedforward adjustments in proximal joints provide the required work output dependent on condition, whilst distal elements can be rapidly altered via feedback to act as springs or dampers [28, 88-91]. Furthermore, kinematic studies on complex terrains show remarkable trends of increased changes, from level, in more distal elements rather than the proximal joints [14, 82, 92-94]. Therefore, how do geckos deal with perturbations if distal elements are restricted in their capacity for adjusting to terrain? Future work should further investigate how geckos adapt their locomotion to perturbations to provide insight of their neuromechanical control, whether as with other species a proximo-distal gradient occurs, or if the adhesive system has constrained and altered their neuromechanical control compared to other lizards. Although most work focuses on the benefits of adhesion, there might be a considerable cost associated with this innovation.

\section{Limb kinematics across lizard species}

We compare our gecko level terrain kinematics to those trajectories available in the literature as an initial analysis between a gecko and other lizards. This was only possible for the hind limb due to lack of data on forelimb kinematics for other lizards. Interestingly, femur retraction was consistent across all lizards with trajectories more or less overlapping during both stance and swing phases (Fig. 4). Conversely femur depression excursion was much smaller during stance in C. bibronii compared to all other lizards, particularly Cnemidophorus tigris (Fig. 4). Femur depression at ES in geckos is therefore unlikely to play an important role in the push-off phase of locomotion.

It is in the more distal limb elements where larger differences between gecko and other lizard kinematics were visible. Knee joint trajectory is similar across the arboreal species i.e. C. bibronii, Anolis and Chamaeleo [13, 94, 95], with all of these species exhibiting a large flexionextension cycle during the stance phase. This is in stark contrast to the other more terrestrial, cursorial species that have a much smaller knee excursion (Fig. 4). This further suggests that ecology may drive the kinematics we observe, especially within a clade of animals.

However, the adhesive system of geckos also appears to play a role, with C. bibronii exhibiting greater ankle excursion during the stance phase than the other lizards (Fig. 4). Chondrodactylus bibronii also maintains the 

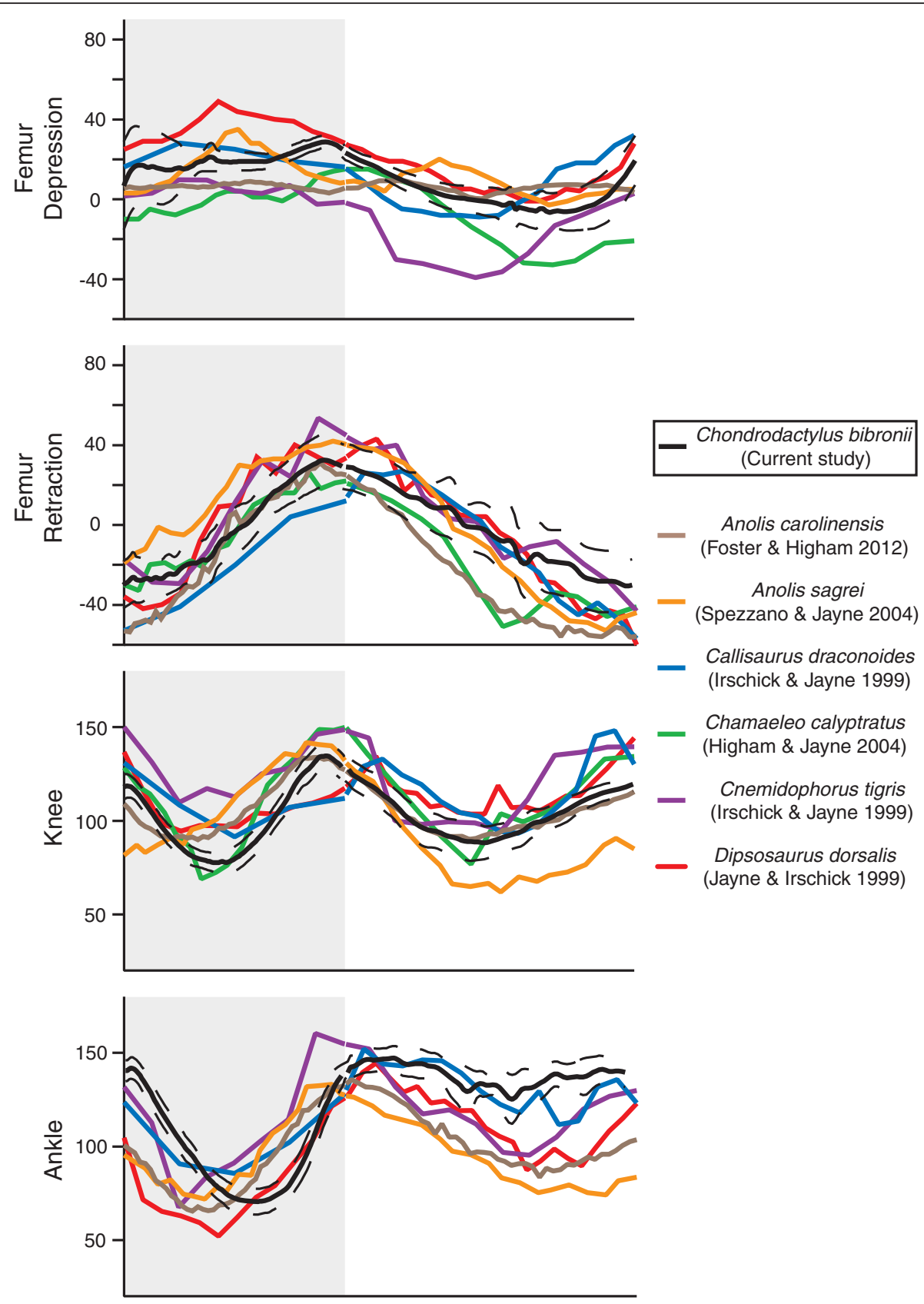

Portion of Stride

Fig. 4 Comparison of hind limb angle trajectory plots across several lizard species. Data for species, apart from the current study's C. bibronii, were obtained from previously published material as stated in the legend. The light grey box represents the stance phase. All data, separately for stance and swing, were interpolated to the same timings, so that speed was not a confounding factor and to observe the similarities and differences between trajectories easily. Femur retraction was remarkably similar across species, but the greatest differences occurred in the most distal element, the ankle. The gecko undergoes greater angular excursion during stance, whilst in the swing holding the ankle at a remarkably fixed angle compared to all other lizard species

ankle at a very constant angle during the swing phase. Both the stance and swing attributes of C. bibronii locomotion suggest that the distal hind limb kinematics may be maintained across conditions to allow the stereotyped movement for engaging the adhesion system. Engaging the adhesive system on both inclines and declines is advantageous [11], as it prevents significant joint kinematic adjustments that would require changes in muscle gearing and neuromechanical control. 


\section{Conclusions}

Chondrodactylus bibronii uses significant de-coupling of the limbs to cope with steep downhill surfaces. The forelimbs undergo few kinematic changes on slopes compared to level terrain. Instead, geckos drastically alter hind limb kinematics, particularly on steep declines. It appears that, although the adhesive system is advantageous on inclines, a trade-off may exist between effective adhesion, and a dynamic response to perturbations, where previous studies have shown that distal limb elements compensate for changes in terrain. Further work should investigate the ability of geckos to cope with terrain perturbations. This innovation has significantly adjusted the biomechanics of gecko locomotion compared to other lizards, resulting in minimal adjustments in distal limb elements on non-level terrain in order to provide rapid and successful adhesion. Neuromuscular recordings would reveal if the recruitment of muscles has also been impacted. If there are changes in both mechanics and muscle activation, then there are likely major shifts in the evolution of neuromechanical control.

\section{Methods}

\section{Animals}

We used six adult Chondrodactylus bibronii (body mass = $12.83 \pm 7.21$ g [mean \pm s.d.]; SVL $=73.3 \pm 9.13 \mathrm{~mm})$, obtained from local commercial suppliers. They were housed individually in 38 litre tanks. Each was fed ad libitum with crickets every other day, kept on a $12 \mathrm{~h}$ light/dark cycle and provided with a $100 \mathrm{~W}$ light. All experimental protocols and animal care were done under and approved by the University of California Riverside Institutional Animal Care and Use Committee following protocol number AUP A-20110038.

Each animal had markers placed on specific landmarks using white nail polish before running trials. Markers were placed on mid-pectoral/pelvic girdle and in-between the two girdles. Markers were further placed on the following joint centres: shoulder/hip, elbow/knee, wrist/ankle, and MCP/MTP (metacarpalphalangeal and metatarsalphalangeal) joints. These markers were only placed on the right side of the body, as only this side was filmed.

\section{Experimental protocol}

Animals were run on a flat runway that was covered in 60 -grit sandpaper and measured $0.96 \mathrm{~m}$ long and $0.14 \mathrm{~m}$ wide. The runway could be rotated to any angle and so the lizards were run on five different slopes: $0,+10,-10$, $+45,-45^{\circ}$. Three high speed video cameras (2 Phantom Miro M150, Vision Research Inc, New Jersey, USA; 1 Photron APX-RS, Photron, San Diego, CA, USA) were synchronously used to get one lateral and two oblique views of the lizards running. All cameras recorded at $1500 \mathrm{~Hz}$, with the shutter speed set to $1 / 7000 \mathrm{~s}$. Animals were encouraged to run across the runway by eliciting an escape response. We obtained at least 3 steady and straight strides for both forelimb and hind limb, condition and individual. We used only strides where the animal performed continuous movement and ran in a straight line. During post processing, we removed significantly unsteady strides in which speed changed more than $30 \%$. After data collection all videos were analysed using only every other frame. This allowed the retention of limb movement detail, particularly during the swing phase, but reduced the number of frames to digitise.

\section{Data analysis}

All markers were digitised using DLT_dv5 [96], custom software for Matlab. Two extra points were also digitised; these were digit III tip on both the manus and the pes. The digitised landmarks provided three-dimensional coordinates for each marker, where the $\mathrm{x}, \mathrm{y}$, and $\mathrm{z}$ direction described the fore-aft, vertical and medio-lateral planes, respectively. All further analysis of the coordinates was processed using custom written code in Matlab (R2013b, The MathWorks, Natick, MA, USA).

A proxy for the centre of mass (CoM) was calculated from the average of three markers along the body midline. This proxy for the CoM was used to calculate overall animal speed and accelerations. Stride length and time were based from when a foot contacted the ground until the subsequent time that same foot contacted the ground. Stride length was only measured along the foreaft axis. Duty factor was the time a foot was in contact with the ground divided by the stride time of that foot.

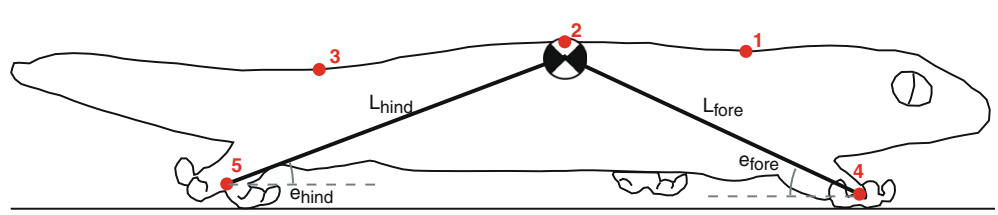

Fig. 5 Schematic representation of measured variables. Markers 1-3 represent the body markers cranially, mid-way and caudually along the midline of the animal. Markers 4 and 5 represent the metacarpalphalangeal (MCP) and metatarsalphalangeal (MTP) joints respectively. $L$ represents the virtual leg length between the centre of mass and the MCP and MTP. e represents the elevation angle along the medio-lateral and vertical axes, whilst the azimuth (not shown in the 2D figure) is the angle between the medio-lateral and fore-aft axes 
Shoulder/hip height was calculated as the vertical distance between the ground and the shoulder/hip landmark.

A virtual leg was calculated as the 3-D distance between the centre of mass $(\mathrm{CoM})$ and the metacarpalphalangeal (MCP) and metatarsalphalangeal (MTP) joints (Fig. 5). This leg measure represents a simplified point-mass model with a mass-less leg $[9,70]$, which describes locomotor gait across humans and non-human animals. Therefore calculating this variable during inclined locomotion allows us to observe how/if overall gait and posture are dependent on the slope. Associated with the leg length were two angles to describe the positioning of the limb. The first was the azimuth angle which describes the foot placement along the fore-aft-medio-lateral plane, measured from the left hand side of the medio-lateral axis. The second was the elevation angle measured along the vertical-medio-lateral plane which measures erectness of leg length (Fig. 5).

Finally, three-dimensional angles were calculated on all limb markers using previously published methods $[13,14,94]$. For elbow/knee, wrist/ankle, MCP/MTP angles, smaller values denote greater flexion at the joint. The shoulder/hip angles (movement of the humerus/ femur) were represented by three different angles; depression, retraction and rotation. Each angle represents a two-dimensional component of the movement in the humerus/femur. Depression is the movement of the humerus/femur along the vertical plane. Angles less than $0^{\circ}$ represent limb elevation and angles greater than $0^{\circ}$ are limb depression. Retraction describes the movement of the humerus/femur along the fore-aft plane, where angles greater than $0^{\circ}$ are protraction and less than $0^{\circ}$ indicate limb retraction. Finally clockwise rotation of the humerus/femur are positive values whilst negative values are anti-clockwise rotation. Pectoral/pelvic rotation was also calculated. Values greater than $0^{\circ}$ indicates that the left shoulder/hip is more anteriorly rotated than the right shoulder/hip. All angles were measured throughout time and at specific time points of footfall (FF), mid stance (MS) and at end stance (ES) events. Angular excursions were also calculated based on the minimum and maximum values during stance. All values provided in text are means \pm s.e.m unless otherwise stated.

\section{Statistical analyses}

All statistical analyses were performed using custom written codes in Matlab. Graphs were generated either in Matlab or Excel. Before performing any statistical analyses, and to remove the effect of individual from the data, a level average per individual was generated. This individual level average was then removed from each individual's sloped conditions. All statistics were performed on the change from level data calculated per each individual. These were the data used to run ANOVAs, using slope as the main fixed factor and individual as the random factor. F-values were adjusted according to procedures set out by Zar [97]. Specifically, we use the mean squares of the interaction term (individual $\mathrm{x}$ slope) as the denominators when determining the F-values for the main slope effect. To directly assess the amount of limb modulation difference between fore- and hind limb, we ran T-tests. The data used for the $\mathrm{t}$-tests were the absolute values of the values once the level mean was removed. Taking the absolute value allowed a comparison of magnitudes rather than direction changes from level.

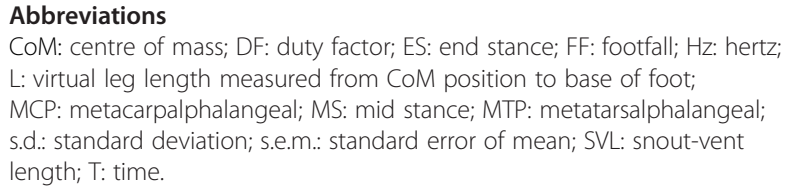

\section{Competing interests}

The authors declare that they have no competing interests.

\section{Authors' contributions}

All authors developed and discussed the project as well as contributed to the writing of the paper. ABJ collected and analysed the data. Both authors read and approved the final manuscript.

\section{Acknowledgements}

We would like to thank Amy Cheu and Shayan Amiri for help with digitising and Clint Collins for help with data collection.

\section{Funding}

This work is supported by an NSF grant (NSF IOS-1147043) to TEH.

Received: 27 September 2015 Accepted: 25 February 2016

Published online: 02 March 2016

\section{References}

1. Biewener A. Biomechanics of mammalian terrestrial locomotion. Science. 1990;250(4984):1097-103. doi:10.1126/science.2251499.

2. Dickinson MH, Farley CT, Full RJ, Koehl MAR, Kram R, Lehman S. How animals move: an integrative view. Science. 2000;288(5463):100-6. doi:10.1126/science.288.5463.100.

3. Farley CT, Glasheen J, McMahon TA. Running springs: speed and animal size. J Exp Biol. 1993;185(1):71-86.

4. Heglund N, Cavagna G, Taylor C. Energetics and mechanics of terrestrial locomotion. III. Energy changes of the centre of mass as a function of speed and body size in birds and mammals. J Exp Biol. 1982;97(1):41-56.

5. Iriarte-Díaz J. Differential scaling of locomotor performance in small and large terrestrial mammals. J Exp Biol. 2002;205(18):2897-908.

6. Taylor CR, Heglund NC, Maloiy GM. Energetics and mechanics of terrestrial locomotion. I. Metabolic energy consumption as a function of speed and body size in birds and mammals. J Exp Biol. 1982;97(1):1-21.

7. Blickhan R, Full RJ. Similarity in multilegged locomotion: bouncing like a monopode. J Comp Physiol A Neuroethol Sens Neural Behav Physiol. 1993:173(5):509-17. doi:10.1007/bf00197760.

8. Full RJ, Koditschek DE. Templates and anchors: neuromechanical hypotheses of legged locomotion on land. J Exp Biol. 1999;202(23):3325-32.

9. McMahon TA, Cheng GC. The mechanics of running: how does stiffness couple with speed? J Biomech. 1990;23 Suppl 1:65-78.

10. Birn-Jeffery AV, Higham TE. The scaling of uphill and downhill locomotion in legged animals. Integr Comp Biol. 2014:54(6):1159-72. doi:10.1093/icb/icu015.

11. Birn-Jeffery AV, Higham TE. Geckos significantly alter foot orientation to facilitate adhesion during downhill locomotion. Biol Letters. 2014;10(10). doi:10.1098/rsbl.2014.0456.

12. Higham TE, Biewener AA. Integration within and between muscles during terrestrial locomotion: effects of incline and speed. J Exp Biol. 2008:211(14): 2303-16. doi:10.1242/jeb.016139. 
13. Foster $\mathrm{KL}$, Higham TE. How forelimb and hindlimb function changes with incline and perch diameter in the green anole, Anolis carolinensis. J Exp Biol. 2012;215(13):2288-300. doi:10.1242/jeb.069856.

14. Jayne BC, Irschick DJ. Effects of incline and speed on the three-dimensional hindlimb kinematics of a generalized iguanian lizard (Dipsosaurus dorsalis). J Exp Biol. 1999;202(2):143-59.

15. Leroux A, Fung J, Barbeau H. Postural adaptation to walking on inclined surfaces: I. Normal strategies. Gait Posture. 2002;15(1):64-74. doi:10.1016/ S0966-6362(01)00181-3.

16. Stevens N, Ratsimbazafy J, Ralainasolo F. Linking Field and Laboratory Approaches for Studying Primate Locomotor Responses to Support Orientation. In: D'Août K, Vereecke EE, editors. Primate Locomotion. Springer New York: Developments in Primatology: Progress and Prospects; 2011. p. 311-33.

17. Higham TE, Korchari PG, McBrayer LD. How muscles define maximum running performance in lizards: an analysis using swing- and stance-phase muscles. J Exp Biol. 2011;214(10):1685-91. doi:10.1242/jeb.051045.

18. Holt NC, Askew GN. Locomotion on a slope in leaf-cutter ants: metabolic energy use, behavioural adaptations and the implications for route selection on hilly terrain. J Exp Biol. 2012;215(15):2545-50. doi:10.1242/jeb.057695.

19. Lammers AR, Earls KD, Biknevicius AR. Locomotor kinetics and kinematics on inclines and declines in the gray short-tailed opossum Monodelphis domestica. J Exp Biol. 2006;209(20):4154-66. doi:10.1242/jeb.02493.

20. Pinch FC, Claussen DL. Effects of temperature and slope on the sprint speed and stamina of the Eastern Fence Lizard, Sceloporus undulatus. J Herpetol. 2003;37(4):671-9. doi:10.1670/183-02.

21. Russell AP, Higham TE. A new angle on clinging in geckos: incline, not substrate, triggers the deployment of the adhesive system. Proc R Soc B Biol Sci. 2009;276(1673):3705-9. doi:10.1098/rspb.2009.0946.

22. Zaaf A, Van Damme R, Herrel A, Aerts P. Spatio-temporal gait characteristics of level and vertical locomotion in a ground-dwelling and a climbing gecko. J Exp Biol. 2001;204(7):1233-46.

23. Nudds RL, Codd JR. The metabolic cost of walking on gradients with a waddling gait. J Exp Biol. 2012;215(15):2579-85. doi:10.1242/jeb.071522.

24. Williams RJ, Nankervis KJ, Colborne GR, Marlin DJ, Schroter RC. Heart rate, net transport cost and stride characteristics of horses exercising at walk and trot on positive and negative gradients. Comparative Exercise Physiology. 2009:6(03):113-9. doi:10.1017/S1755254009990092.

25. Kivell TL, Schmitt D, Wunderlich RE. Hand and foot pressures in the aye-aye (Daubentonia madagascariensis) reveal novel biomechanical trade-offs required for walking on gracile digits. J Exp Biol. 2010;213(9):1549-57. doi:10.1242/jeb.040014.

26. Shapiro LJ, Young JW. Is primate-like quadrupedalism necessary for finebranch locomotion? A test using sugar gliders (Petaurus breviceps). J Hum Evol. 2010;58(4):309-19. doi:10.1016/j.jhevol.2009.12.002.

27. Hoyt DF, Wickler SJ, Garcia SF. Oxygen consumption (ํO2) during trotting on a $10 \%$ decline. Equine Vet J. 2006;38(S36):573-6. doi:10.1111/j.2042-3306. 2006.tb05607.x.

28. Gillis $G B$, Biewener AA. Effects of surface grade on proximal hindlimb muscle strain and activation during rat locomotion. J Appl Physiol. 2002; 93(5):1731-43. doi:10.1152/japplphysiol.00489.2002.

29. Raab JL, Eng P, Waschler RA. Metabolic cost of grade running in dogs. J Appl Physiol. 1976:41(4):532-5.

30. Smith JL, Carlson-Kuhta P, Trank TV. Forms of forward quadrupedal locomotion. III. A comparison of posture, hindlimb kinematics, and motor patterns for downslope and level walking. J Neurophysiol. 1998;79(4):1702-16.

31. Johnson MK, Russell AP, Bauer AM. Locomotor morphometry of the Pachydactylus radiation of lizards (Gekkota: Gekkonidae): a phylogenetically and ecologically informed analysis. Can J Zool. 2005:83(12):1511-24. doi:10.1139/z05-112.

32. Gamble T, Greenbaum E, Jackman TR, Russell AP, Bauer AM. Repeated origin and loss of adhesive toepads in Geckos. PLOS ONE. 2012;7(6). doi:10.1371/ journal.pone.0039429.

33. Autumn K, Liang YA, Hsieh ST, Zesch W, Chan WP, Kenny TW, et al. Adhesive force of a single gecko foot-hair. Nature. 2000;405(6787):681-5.

34. Stewart WJ, Higham TE. Passively stuck: death does not affect gecko adhesion strength. Biol Lett. 2014;10(12):20140701.

35. Ruibal R, Ernst V. The structure of the digital setae of lizards. J Morphol. 1965;117(3):271-93. doi:10.1002/jmor.1051170302.

36. Russell AP. Contribution to functional-analysis of foot of tokay, gekko-gecko (Reptilia-Gekkonidae). J Zool. 1975;176(4):437-76.
37. Russell AP. The morphological basis of weight-bearing in the scansors of the tokay gecko (Reptilia: Sauria). Can J Zool. 1986;64(4):948-55. doi:10.1139/286-144.

38. Autumn K, Peattie AM. Mechanisms of adhesion in geckos. Integr Comp Biol. 2002:42(6):1081-90. doi:10.1093/icb/42.6.1081.

39. Autumn K, Dittmore A, Santos D, Spenko M, Cutkosky M. Frictional adhesion: a new angle on gecko attachment. J Exp Biol. 2006;209(18):3569-79. doi:10.1242/ jeb.02486.

40. Izadi H, Stewart KME, Penlidis A. Role of contact electrification and electrostatic interactions in gecko adhesion. J R Soc Interface. 2014;11(98). doi:10.1098/rsif.2014.0371.

41. Autumn K, Sitti M, Liang YA, Peattie AM, Hansen WR, Sponberg S, et al. Evidence for van der Waals adhesion in gecko setae. Proc Natl Acad Sci. 2002:99(19):12252-6. doi:10.1073/pnas.192252799.

42. Chen B, Wu PD, Gao H. Hierarchical modelling of attachment and detachment mechanisms of gecko toe adhesion. Proc R Soc A Math Phys Eng Sci. 2008;464(2094):1639-52. doi:10.1098/rspa.2007.0350.

43. Gao H, Wang X, Yao H, Gorb S, Arzt E. Mechanics of hierarchical adhesion structures of geckos. Mechanics of Materials. 2005;37(2-3):275-85. doi:10.1016/j.mechmat.2004.03.008

44. Gillies AG, Henry A, Lin H, Ren A, Shiuan K, Fearing RS, et al. Gecko toe and lamellar shear adhesion on macroscopic, engineered rough surfaces. J Exp Biol. 2014;217(2):283-9. doi:10.1242/jeb.092015.

45. Hagey T, Puthoff J, Holbrook M, Harmon L, Autumn K. Variation in setal micromechanics and performance of two gecko species. Zoomorphology. 2014;133(2):111-26. doi:10.1007/s00435-013-0207-2.

46. Hill GC, Soto DR, Peattie AM, Full RJ, Kenny TW. Orientation angle and the adhesion of single gecko setae. J R Soc Interface. 2011;8(60):926-33. doi:10.1098/rsif.2010.0720.

47. Tian Y, Pesika N, Zeng H, Rosenberg K, Zhao B, McGuiggan P, et al. Adhesion and friction in gecko toe attachment and detachment. Proc Natl Acad Sci. 2006;103(51):19320-5. doi:10.1073/pnas.0608841103.

48. Higham TE, Birn-Jeffery AV, Collins CE, Hulsey CD, Russell AP. Adaptive simplification and the evolution of gecko locomotion: Morphological and biomechanical consequences of losing adhesion. Proc Natl Acad Sci. 2015;112(3):809-14. doi:10.1073/pnas.1418979112.

49. Farley CT, Ko TC. Mechanics of locomotion in lizards. J Exp Biol. 1997;200(16):2177-88.

50. Irschick DJ, Vanhooydonck B, Herrel A, Andronescu A. Effects of loading and size on maximum power output and gait characteristics in geckos. J Exp Biol. 2003;206(22):3923-34. doi:10.1242/jeb.00617.

51. Li H, Dai Z, Shi A, Zhang H, Sun J. Angular observation of joints of geckos moving on horizontal and vertical surfaces. Chinese Sci Bull. 2009;54(4):592-8. doi:10.1007/s11434-009-0077-7.

52. Wang Z, Wang J, Ji A, Zhang Y, Dai Z. Behavior and dynamics of gecko's locomotion: The effects of moving directions on a vertical surface. Chinese Sci Bull. 2011;56(6):573-83. doi:10.1007/s11434-010-4082-7.

53. Autumn K, Hsieh ST, Dudek DM, Chen J, Chitaphan C, Full RJ. Dynamics of geckos running vertically. J Exp Biol. 2006;209(2):260-72. doi:10.1242/jeb.01980.

54. Collins CE, Russell AP, Higham TE. Subdigital adhesive pad morphology varies in relation to structural habitat use in the Namib Day Gecko. Funct Ecol. 2014:n/a-n/a. doi:10.1111/1365-2435.12312.

55. Branch WR. Field Guide to Snakes and Other Reptiles of Southern Africa. Cape Town, South Africa: Struik; 1998.

56. Webster NB, Johnson MK, Russell AP. Ontogenetic scaling of scansorial surface area and setal dimensions of Chondrodactylus bibronii (Gekkota: Gekkonidae): testing predictions derived from cross-species comparisons of gekkotans. Acta Zool. 2009;90(1):18-29. doi:10.1111/j.1463-6395.2008. 00324.x.

57. Schmidt A, Fischer MS. The kinematic consequences of locomotion on sloped arboreal substrates in a generalized (Rattus norvegicus) and a specialized (Sciurus vulgaris) rodent. J Exp Biol. 2011;214(15):2544-59. doi:10.1242/jeb.051086.

58. Claussen DL, Lim R, Kurz M, Wren K. Effects of slope, substrate, and temperature on the locomotion of the ornate box turtle, Terrapene ornata. Copeia. 2002;2002(2):411-8. doi:10.2307/1448055.

59. Irschick DJ, Jayne BC. A field study of the effects of incline on the escape locomotion of a bipedal lizard, callisaurus draconoides. Physiol Biochem Zool. 1999:72(1):44-56. doi:10.1086/316641.

60. Jayne BC, Ellis RV. How inclines affect the escape behaviour of a dunedwelling lizard,Uma scoparia. Anim Behav. 1998;55(5):1115-30. doi:http://dx. doi.org/10.1006/anbe.1997.0655. 
61. Prenter J, Fanson BG, Taylor PW. Whole-organism performance and repeatability of locomotion on inclines in spiders. Anim Behav. 2012;83(5): 1195-201. doi:10.1016/j.anbehav.2012.02.010.

62. Crook TC, Wilson A, Hodson-Tole E. The effect of treadmill speed and gradient on equine hindlimb muscle activity. Equine Vet J. 2010;42:412-6. doi:10.1111/j.2042-3306.2010.00222.x.

63. Gottschall JS, Kram R. Ground reaction forces during downhill and uphill running. J Biomech. 2005;38(3):445-52. doi:10.1016/j.jbiomech.2004.04.023.

64. Lauer SK, Hillman RB, Li L, Hosgood GL. Effects of treadmill inclination on electromyographic activity and hind limb kinematics in healthy hounds at a walk. Am J Vet Res. 2009;70(5):658-64. doi:10.2460/ajvr.70.5.658.

65. Lees J, Folkow L, Stokkan K-A, Codd J. The metabolic cost of incline locomotion in the Svalbard rock ptarmigan (Lagopus muta hyperborea): the effects of incline grade and seasonal fluctuations in body mass. J Exp Biol. 2013;216(8):1355-63. doi:10.1242/jeb.078709.

66. Nyakatura JA, Fischer MS, Schmidt M. Gait parameter adjustments of cotton-top tamarins (Saguinus oedipus, Callitrichidae) to locomotion on inclined arboreal substrates. Am J Phys Anthropol. 2008;135(1):13-26. doi:10.1002/ajpa.20699.

67. Schmidt A. Locomotion in degus on terrestrial substrates varying in orientation - implications for biomechanical constraints and gait selection. Zoology. 2014(0). doi:10.1016/j.zool.2013.08.009.

68. Roberts TJ, Higginson BK, Nelson FE, Gabaldón AM. Muscle strain is modulated more with running slope than speed in wild turkey knee and hip extensors. J Exp Biol. 2007;210(14):2510-7. doi:10.1242/jeb.003913.

69. Biewener A, Taylor C. Bone strain: a determinant of gait and speed? J Exp Biol. 1986;123(1):383-400.

70. Blickhan R. The spring-mass model for running and hopping. J Biomech. 1989;22(11-12):1217-27.

71. Marsh RL, Ellerby DJ, Carr JA, Henry HT, Buchanan Cl. Partitioning the energetics of walking and running: swinging the limbs is expensive. Science. 2004;303(5654):80-3. doi:10.1126/science.1090704.

72. Umberger BR. Stance and swing phase costs in human walking. J R Soc Interface. 2010. doi:10.1098/rsif.2010.0084.

73. Birn-Jeffery AV, Daley MA. Birds achieve high robustness in uneven terrain through active control of landing conditions. J Exp Biol. 2012;215(12):2117-27. doi:10.1242/jeb.065557.

74. Blum Y, Vejdani HR, Birn-Jeffery AV, Hubicki CM, Hurst JW, Daley MA. Swingleg trajectory of running Guinea fowl suggests task-level priority of force regulation rather than disturbance rejection. PLoS One. 2014;9(6):e100399. doi:10.1371/journal.pone.0100399.

75. Daley MA, Biewener AA. Running over rough terrain reveals limb control for intrinsic stability. P Natl Acad Sci USA. 2006;103(42):15681-6. doi:10.1073/ pnas.0601473103.

76. Blum Y, Rummel J, Seyfarth A. Advanced Swing Leg Control for Stable Locomotion. In: Berns K, Luksch T, editors. Autonome Mobile Systeme 2007. Heidelberg: Springer; 2007. p. 301-7.

77. Seyfarth A, Geyer $H$, Herr $H$. Swing-leg retraction: a simple control model for stable running. J Exp Biol. 2003;206(Pt 15):2547-55.

78. Blum Y, Birn-Jeffery A, Daley MA, Seyfarth A. Does a crouched leg posture enhance running stability and robustness? J Theor Biol. 2011;281(1):97-106. doi:10.1016/j.jtbi.2011.04.029.

79. Daley MA, Usherwood JR. Two explanations for the compliant running paradox: reduced work of bouncing viscera and increased stability in uneven terrain. Biol Lett. 2010;6(3):418-21. doi:10.1098/rsbl.2010.0175.

80. Carlson-Kuhta P, Trank TV, Smith JL. Forms of forward quadrupedal locomotion. II. A comparison of posture, hindlimb kinematics, and motor patterns for upslope and level walking. J Neurophysiol. 1998;79(4):1687-701.

81. Krause C, Fischer MS. Biodynamics of climbing: effects of substrate orientation on the locomotion of a highly arboreal lizard (Chamaeleo calyptratus). J Exp Biol. 2013;216(8):1448-57. doi:10.1242/jeb.082586.

82. Schmidt A, Fischer MS. Arboreal locomotion in rats - the challenge of maintaining stability. J Exp Biol. 2010;213(21):3615-24. doi:10.1242/jeb.045278.

83. Chen JJ, Peattie AM, Autumn K, Full RJ. Differential leg function in a sprawled-posture quadrupedal trotter. J Exp Biol. 2006;209(2):249-59. doi:10.1242/jeb.01979.

84. Lee DV. Effects of grade and mass distribution on the mechanics of trotting in dogs. J Exp Biol. 2011;214(3):402-11. doi:10.1242/jeb.044487.

85. Higham TE, Jayne BC. Locomotion of lizards on inclines and perches: hindlimb kinematics of an arboreal specialist and a terrestrial generalist. J Exp Biol. 2004;207(2):233-48. doi:10.1242/jeb.00763.
86. Russell AP, Oetelaar GS. Limb and digit orientation during vertical clinging in Bibron's gecko, Chondrodactylus bibronii (A. Smith, 1846) and its bearing on the adhesive capabilities of geckos. Acta Zool. 2015:n/a-n/a. doi:10.1111/ azo.12128.

87. Zaaf A, Herrel A, Aerts P, De Vree F. Morphology and morphometrics of the appendicular musculature in geckoes with different locomotor habits (Lepidosauria). Zoomorphology. 1999;119(1):9-22. doi:10.1007/s0043500 50077.

88. Daley MA, Biewener AA. Muscle force-length dynamics during level versus incline locomotion: a comparison of in vivo performance of two guinea fowl ankle extensors. J Exp Biol. 2003:206(17):2941-58. doi:10.1242/Jeb. 00503.

89. Daley MA, Felix G, Biewener AA. Running stability is enhanced by a proximo-distal gradient in joint neuromechanical control (vol 210, pg 383, 2006). J Exp Biol. 2007:210(4):383-94. doi:10.1242/Jeb.004226.

90. Nisky I, Baraduc P, Karniel A. Proximodistal gradient in the perception of delayed stiffness. J Neurophysiol. 2010;103(6):3017-26. doi:10.1152/jn.00939. 2009.

91. Roberts TJ, Belliveau RA. Sources of mechanical power for uphill running in humans. J Exp Biol. 2005;208(10):1963-70. doi:10.1242/jeb.01555.

92. Clark AJ, Higham TE. Slipping, sliding and stability: locomotor strategies for overcoming low-friction surfaces. J Exp Biol. 2011:214(8):1369-78. doi:10.1242/jeb.051136

93. Moritz CT, Greene SM, Farley CT. Neuromuscular changes for hopping on a range of damped surfaces. J Appl Physiol. 2004;96(5):1996-2004. doi:10.1152/japplphysiol.00983.2003.

94. Spezzano LC, Jayne BC. The effects of surface diameter and incline on the hindlimb kinematics of an arboreal lizard (Anolis sagrei). J Exp Biol. 2004; 207(12):2115-31. doi:10.1242/jeb.00995.

95. Higham TE, Jayne BC. In vivo muscle activity in the hindlimb of the arboreal lizard, Chamaeleo calyptratus: general patterns and the effects of incline. J Exp Biol. 2004;207(2):249-61. doi:10.1242/jeb.00745.

96. Hedrick TL. Software techniques for two- and three-dimensional kinematic measurements of biological and biomimetic systems. Bioinspir Biomim. 2008:3(3):034001.

97. Zar JH. Biostatistical Analysis. New Jersey: Prentice Hall; 1996.

\section{Submit your next manuscript to BioMed Central and we will help you at every step:}

- We accept pre-submission inquiries

- Our selector tool helps you to find the most relevant journal

- We provide round the clock customer support

- Convenient online submission

- Thorough peer review

- Inclusion in PubMed and all major indexing services

- Maximum visibility for your research

Submit your manuscript at www.biomedcentral.com/submit 